\title{
Art and Engineering
}

\author{
Oana Gui \\ Karabük University, Turkey \\ 100. Y,I 78020 Karabük/Türkiye \\ oanagui@karabuk.edu.tr
}

\author{
Radu Moraru \\ Art and Design University Cluj-Napoca, Romania \\ Piața Unirii 31, 4000, Cluj-Napoca, România \\ radu.moraru@uad.ro
}

\section{INTRODUCTION}

The demo intends to present some results of an experiment involving undergraduate students from different fields, such as fine arts and electronics or computers. The declared objective of the experiment is to create interactive sketches in Processing, which will run in active mode and receive input from the mouse, the keyboard and also from other external sensor systems (systems measuring temperature, acceleration, pressure etc.). The undeclared objective of the project is to addresses the question of harnessing individual differences towards improving interdisciplinary teams.

\section{ART AND ENGINEERING EXPERIMENT}

The experiment involves students from Karabük University, Turkey, together with students from Art and Design University Cluj and Technical University "Gheorghe Asachi“ Iași, Romania.

By learning how to create sketches in Processing those who have no experience in computer programming will discover the meaning of an algorithm and will be able to create their own visual experiments. At the same time, those with a technical background will discover the artistic potential of images, sounds and animation. Their technical skills will be used to create different ways of interacting with computers by providing input from external systems to alter different parameters of the interactive sketches.

\subsection{Undeclared Objective}

At first the study focuses on differences in personality along Jung's theory, which differentiates people differences in how they perceive and how they decide. The model will be completed with two other dimensions (Extraversion - Introversion, and Judging - Perceiving) by use of the Myers-Briggs Type Indicator personality inventory. The theory can be directly linked to stages of problem solving, and therefore directly linked to practical application. The next step is to understand how differences occur as adaptations to the parental environment, in the light of the Personality Adaptations theory and the Life Script concept.

\subsection{The Engineering}

Same time, the ongoing experiment is developing hardware capable of introducing an element of randomness into the interactive sketches using input from different sensory systems. The input is based on wireless signals sent from a microcontroller, received from strain gauges, accelerometers and other type of sensors. At this moment the signals are processed using a wireless single chip microcontroller unit, SimpleLink CC3200 from Texas Instruments, with a program written in Energia software, but changes may occur.

\section{ACKNOWLEDGMENTS}

Special thanks to the students Cătălin Popescu, Constantin Holban (Iași), Kenan Ünal, Serdar Çelik, Ibrahim Nadir Çetin and Kemal Çördük (Karabük), who enthusiastically joined the experiment.

\section{REFERENCES}

Bohnacker, H., Gross, B., \& Laub, J., (2012) Lazzeroni, C. (ed.), Generative Design: Visualize, Program and Create with Processing, Princeton Architectural Press, Princeton.

Hirsh, S. K. \& Kummerow, J. (2000) Introduction to Type in Organisations, Oxford Psychologists Press, Oxford.

Joines, V. \& Stewart, I. (2000) Personality Adaptations, Lifespace Publishing, Nottingham and Chapel Hill.

Gui, O., Ailincăi, C., Săcărea, Ch., Georgescu, M., \& loannidou, F.G, (2007) Interdisciplinary research projects: trade-offs or synergies? International Conference on Interdisciplinarity in Education (ICIE 2007), Athens, Greece, March 15-17, pp. 300-304. 


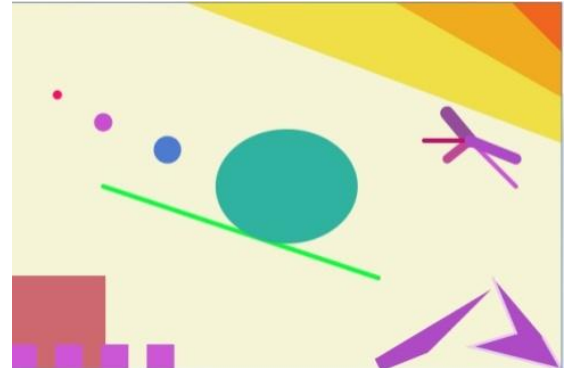

Figure 1: First static sketch that demonstrates the command of over drawing basic objects

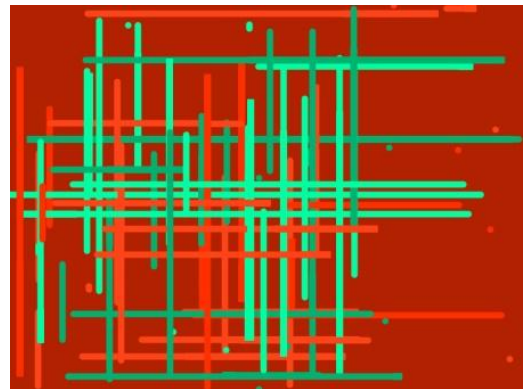

Figure 3: Snapshot from a sketch that demonstrates the command over drawing dynamically in processing

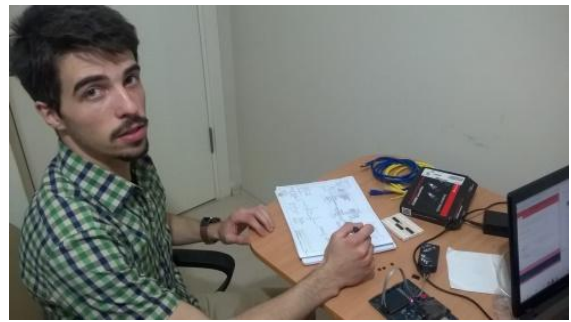

Figure 5: The hardware enthusiast

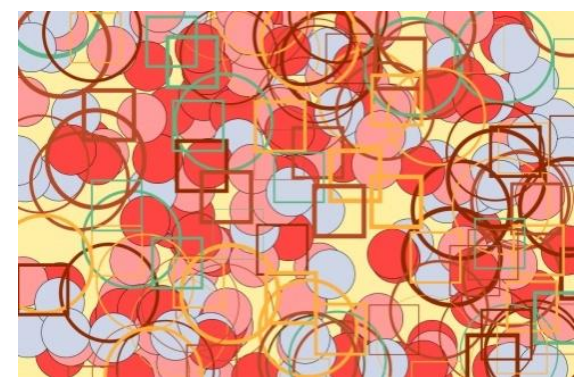

Figure 2: Sketch that demonstrates the ability to use code blocks, variables, arrays, loops and colour palettes

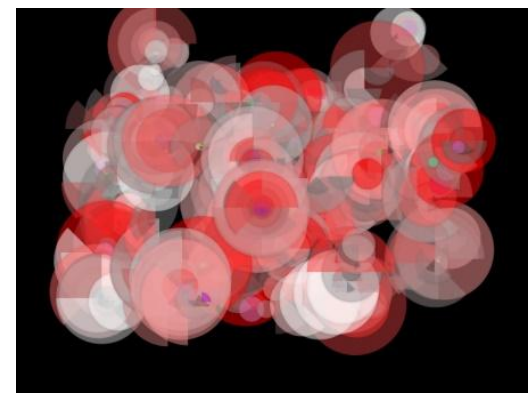

Figure 4: Snapshot from an interactive sketch in processing

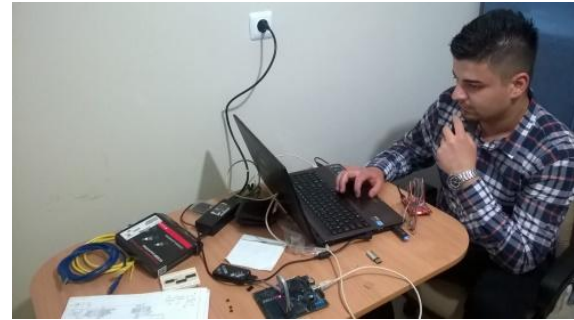

Figure 6: The software enthusiast

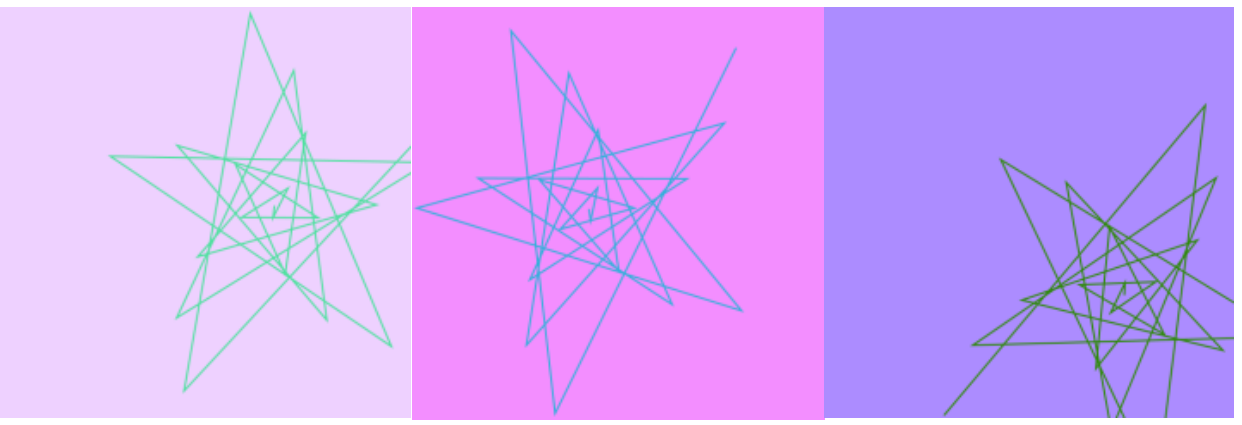

Figure 7: Snapshots from a dynamic sketch in Processing that runs in active mode and receives input from mouse and keyboard - a canvas that remains blank until the user begins interacting with it 